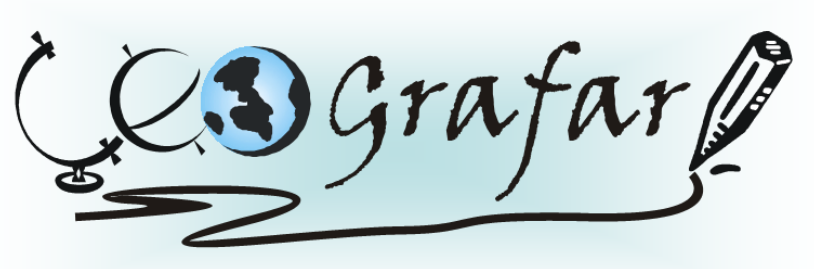

Revista Eletrônica do Programa de Pós-Graduação em Geografia - UFPR

\title{
ESPAÇOS PÚBLICOS, IMAGENS DO URBANO E PEDRO ALMODÓVAR: A CIDADE CINEMÁTICA DE UM CINEASTA PÓS-MODERNO
}

\section{PUBLIC SPACES, URBAN IMAGES AND PEDRO ALMODÓVAR: THE CINEMATIC CITY OF A POSTMODERN FILMMAKER}

\author{
(Recebido em 07.11.2012; Aceito em: 18.04.2013)
}

Karina Eugenia Fioravante Doutoranda do Programa de Pós-Graduação em Geografia Universidade Federal do Rio de Janeiro Rio de Janeiro, RJ, Brasil e-mail: karina_frr@hotmail.com

\begin{abstract}
RESUMO
Nosso objetivo nesse artigo é demonstrar a grande potencialidade do cinema para análises geográficas, fato que vem sendo enfatizados por alguns geógrafos engajados principalmente com a Nova Geografia Cultural. Para tanto, elegemos como foco de nosso interesse a filmografia do cineasta espanhol Pedro Almodóvar a fim de discutir a construção da cidade cinemática e, em especial, as imagens relacionadas à representação dos espaços públicos da cidade de Madrid. Pedro Almodóvar é uma das figuras mais importantes da cena cultural espanhola e seus filmes vêm sendo explorados por inúmeras áreas do conhecimento. Entretanto, na Geografia sua filmografia permanece inexplorada, mesmo apresentando inúmeros elementos os quais podem ser problematizados a partir de uma análise espacial. Nesse artigo exploramos uma faceta específica de seus filmes, a cidade, guiados por uma orientação estética que vêm sendo fortemente relacionada à Almodóvar, o pós-modernismo. Nosso texto se constrói da seguinte forma: primeiramente apresentamos algumas considerações teóricas que auxiliaram na construção da problemática do artigo. Essas considerações se debruçam principalmente sobre as ideias de pós-modernidade, cinema e espaços públicos. Posteriormente, trazemos uma discussão acerca das cidades e o cinema a fim de elucidar como essas duas temáticas vêm sendo abordadas pela Geografia. Por fim, mergulhamos nas imagens de Pedro Almodóvar, discutindo como a estética pós-moderna e a influência da
\end{abstract}


Movida Madrileña criam uma representação particular dos espaços públicos nos filmes do cineasta.

Palavras-chave: Cinema e Geografia; Cidade Cinemática; Espaços Públicos; PósModernidade; Pedro Almodóvar.

\section{ABSTRACT}

Our goal in this article is to demonstrate the great potential of cinema for geographical analysis, a fact that has been emphasized by some geographers engaged mainly with the new Cultural geography. To this end, we focus our interest to Spanish Filmmaker Pedro Almodovar's Filmography in order to discuss the construction of the cinematic city and, in particular, the images related to the representation of the public spaces of the city of Madrid. Pedro Almodóvar is one of the leading figures of the Spanish cultural scene and his films have been exploited by numerous areas of knowledge. However, his filmography remains unexplored in Geography, even showing a number of elements which can be problematized from a spatial analysis. In this article we explore a specific facet of his films, the city, guided by an aesthetic orientation that have been strongly linked to Almodóvar, postmodernism. Our text is built as follows: first we present some theoretical considerations that helped in the construction of the problematic article. These considerations approach mainly on the ideas of post-modernity, cinema and public spaces. Later, we have a discussion about the cities and cinema in order to elucidate how these two issues are being addressed by geography. Finally, we dive in the images of Pedro Almodóvar, discussing how postmodern aesthetics and the influence of the Movida Madrileña create a particular representation of public spaces in the filmmaker's movies.

Keywords: Cinema and Geography; Cinematic City; Public Spaces; Postmodernism; Pedro Almodóvar.

\section{Palavras Iniciais}

$\mathrm{Na}$ apresentação de uma de suas obras, Castro, Gomes e Corrêa (1996) nos trazem que a geografia sempre esteve associada à ideia das explorações. Essas descobertas, anteriormente realizadas principalmente por viajantes e cosmógrafos enfatizavam a aventura de se deparar com o novo, com o desconhecido. A aventura de explorar, de descobrir não cessou, apenas apresentou uma profunda mudança em seu sentido. Os 'novos mundos' da atualidade não são mais representados por terras desconhecidas e locais nunca visitados, mas sim, são extratos do nosso cotidiano descobertos a partir de formas de olharmos, de concebermos e relacionarmos esses aspectos com percursos temáticos inéditos. 
Para os autores, nossas explorações geográficas atuais se remetem a ideia de repensar antigos processos de conhecimento para assim conceber novos aspectos, novos posicionamentos e novas abordagens. Ou seja, a aventura da descoberta continua, apenas com diferentes pretensões e instrumentos. Outras temáticas em diferentes contextos são exploradas.

Da mesma forma, com o desenvolvimento da nova geografia cultural a partir da década de 1990, surgem novas possibilidades investigativas, as quais podem ser discutidas com legitimidade e principalmente, com um ponto de vista especificamente geográfico. A abertura que esse subcampo nos confere é um extraordinário estímulo de valorização às problemáticas de pesquisas até então negligenciadas. Temáticas ousadas e inovadoras são relevantes na medida em que incitam o processo de renovação das discussões já estabelecidas e até mesmo criam novas metodologias originais (GOMES, 2008).

$O$ desafio desse artigo é pensar geograficamente as imagens produzidas pelo cinema, evidenciando, da mesma forma, que este pode se constituir enquanto um rico quadro de referência para análises geográficas ou, utilizando a ideia dos autores, enquanto um 'novo mundo' a ser explorado. Como trouxe Cosgrove (1989), a imaginação pode transformar a sociedade e seu ambiente natural em uma unidade espacial, onde as formas, objetos e outros atributos são impregnados por símbolos, signos e sentidos. Ou seja, ela é capaz de criar imagens do real que são (re) significadas e $(\mathrm{re})$ elaboradas constantemente mediante a experiência concreta dos sujeitos.

Vivemos, hoje, uma verdadeira rapsódia imagética, visto a imensa quantidade de imagens que chegam até nós, não somente através das produções dos meios de comunicação, como telejornais e novelas, mas também das imagens construídas pelo cinema, fotografia, etc. É válido lembrarmos que, atualmente, temos possibilidade de entrar em contato com uma quantidade imensa de produções imagéticas, não somente a partir de nossa experiência concreta, mas, também, por meio de ambientes virtuais que nos permitem acessá-las em uma escala temporal relativamente curta, garantindo assim uma disseminação para um público ainda maior.

Entretanto, a geografia tem dedicado limitado interesse pelas questões visuais, ignorando o fato de que, as imagens estão presentes na grande maioria das 
formas de relações sociais (ROSE, 2001), adquirindo, da mesma forma, uma considerável parcela de importância na construção de "geografias imaginárias" que (re) significam e ganham amplitude nos problemas de simbolização das formas e das ações de indivíduos no espaço.

Para essa proposta escolhemos a filmografia do cineasta espanhol Pedro Almodóvar, objetivando compreender a representação das imagens do urbano em sua relação com cenários construídos a partir de uma estética da pós-modernidade. Em seu currículo constam cerca de quarenta obras, divididas entre curtas e longas metragens, aparições como ator e trabalhos de produção. Para nossa proposta optamos por contemplar apenas os dezoito ${ }^{1}$ longa metragens de Almodóvar, considerando que a partir desses materiais imagéticos podemos tecer reflexões mais densas, levando em consideração, da mesma forma, que essas produções refletem em sua totalidade a estética e liberdade de criação do cineasta, nos garantindo, portanto, uma compreensão legítima de sua forma de construir imagens da realidade.

Autores como Santana (2007) discutem que podemos analisar a filmografia de Almodóvar a partir de dois momentos essenciais. No primeiro deles, visível em suas oito produções iniciais, podemos observar a forte influência do movimento contra cultural espanhol denominado de La Movida. Posteriormente, costuma-se afirmar que o cineasta apresentou maior maturidade em suas criações, juntamente com a necessidade de expressar sua individualidade. A exaltação do feminino, do polêmico, onde rir e sofrer demasiadamente, não parecem mais ser suficientes, são características que sobressaltam em seus últimos dez filmes.

É interessante observar que, apesar dessa periodicidade que costuma caracterizar a produção de Almodóvar, observamos, desde seu primeiro longa metragem, uma maneira de criar muito peculiar que nos remete, quase que instantaneamente, a uma linguagem cinematográfica respaldada por esta "nova" forma de ser e estar no mundo. Intitulada sob o nome de pós-modernidade, essa tendência, se assim podemos afirmar, vem influenciando as mais diversas esferas da vida social, seja através das calorosas discussões que estão sendo instituídas na

\footnotetext{
${ }^{1}$ Seus longas são: Pepe, Luci, Bom y otras chicas de montón (1980), Laberinto de Passiones (1982), Entre Tinieblas (1983), ¿Qué he hecho yo para merecer esto? (1984), Matador (1986), La Ley del Deseo (1987), Mujeres al borde de un ataque de nervios (1988), ¿Átame! (1990), Tacones Lejanos (1991), Kika (1993), La flor de mi segreto (1995), Carne Trémula (1997), Todo sobre mi madre (1999), Hable con ella (2002), La Mala Educación (2004), Volver (2006), Los Abrazos Rotos (2009), La Piel que Habito (2011).
} 
Academia, seja através de um estilo diferenciado de pintura, arquitetura, fotografia, entre outros. O cinema, arte revolucionária de captar imagens com impressão de movimento, trazida pelo cinematógrafo dos irmãos Lumière no final do século XIX, obviamente, não fica fora desse hall.

O termo é, sem dúvida, um dos mais polêmicos em circulação nas teorias culturais, alcançando uma gama imensa de defensores e de críticos. Sua influência pode ser sentida no mundo cinematográfico a partir de premissas que aparentam rejeitar, principalmente, o purismo e o elitismo identificados como características do alto modernismo.

Jameson (2004) afirma que ocorreu uma transformação da imagem na pósmodernidade, sendo possível observarmos, ao longo do século $X X$, três etapas bem distintas dentro da teoria da visão; um momento colonial (ou sartreano), um momento burocrático (ou foucaultiano), e por fim, um momento pós-moderno. $\mathrm{O}$ último, foco de nosso interesse para esse projeto, Jameson (2004) teoriza como o momento da sociedade da imagem, época em que somos bombardeados diariamente por uma gama infinita de imagens, vivendo e consumindo culturas de formas novas e diferentes.

Entretanto, essa exaltação do imagético traz consigo problemas paradoxais, relacionados principalmente com a maior estetização da realidade. Com um viés de crítico, o autor questiona a necessidade de construirmos teorias e conceitos que sejam capazes de explicar esse novo momento, já que, se a realidade tornou-se demasiadamente visual, tendendo, portanto, para a imagem, tornou-se cada vez mais difícil conceituar uma experiência da imagem que seja capaz de se distinguir das demais.

Pedro Almodóvar é figura de proa nessa "nova" forma de filmar, e nosso interesse principal nesse artigo, é compreender de que forma essa estética ou estilo, se é que dessa forma podemos qualificá-lo, se faz perceber na criação das imagens urbanas na filmografia do cineasta. É essa a questão que buscamos problematizar no decorrer desse artigo.

Esse texto se estrutura a partir da seguinte maneira: primeiramente, trazemos algumas considerações teóricas acerca das noções de pós-modernidade, imagens e espaços públicos, as quais utilizamos como aporte para discutir as imagens da cidade produzidas pela filmografia de Pedro Almodóvar Posteriormente, discutimos 
sobre o cinema e sua inter-relação com a Geografia, objetivando trazer as principais formas como a Geografia esta problematizando as imagens em movimento do Cinema. Focamos principalmente nos conceitos e metodologias que são utilizadas na temática relacionada às representações da cidade no cinema. Por fim, mergulhamos nas imagens de Pedro Almodóvar, demonstrando como o cineasta constrói representações urbanas, especificamente, da cidade de Madrid, central nos filmes e tramas do cineasta espanhol.

\section{Algumas reflexões sobre imagens, pós-modernidade e espaços públicos: uma dimensão explicativa}

O objetivo desse artigo é compreender a representação das imagens urbanas a partir dos cenários pós-modernos construídos pela filmografia de Pedro Almodóvar. Tal compreensão exige três eixos fundamentais de análise para estruturação da problemática do texto. Primeiramente, faz-se necessário delinearmos nosso posicionamento conceitual, conferindo da mesma forma, um caráter especificamente geográfico a nossa abordagem levando em consideração o referencial empírico escolhido, ou seja, os espaços urbanos construídos pela filmografia do cineasta.

Duas cidades espanholas aparecem como centrais nos filmes de Pedro Almodóvar, a capital Madrid e a cidade catalã Barcelona. Representadas a partir de pontos de vistas diferenciados e mediante a vivência espacial de diversos personagens, é em direção a essas espacialidades que objetivamos voltar nosso olhar, almejando compreender como a filmografia de Almodóvar nos traz representações, significações de suas morfologias, bem como das ações e práticas sociais que criam essa mixité ao qual denominamos cidade. Utilizaremos, para tanto, a noção de espaço público, compreendendo-o como o lugar onde, por excelência, a multiplicidade exerce a arte da convivência, através da realização de múltiplas trocas e interações cotidianas. A partir dela, somos capazes de produzir uma identidade urbana, obtendo um sentido particular de urbanidade, o que nos confere uma imagem da cidade.

O segundo está pautado na ideia de entrelaçarmos essa noção com as proposições trazidas por um contexto que vem sendo denominado por vários 
autores de pós-moderno. Essa tarefa não é simples, muito pelo contrário, é desafiadora uma vez que, apesar de vasta, a bibliografia que investiga a pósmodernidade é pouco concisa e falha no sentido de nos conferir uma ideia clara e precisa a seu respeito, fato compreensível devido a sua própria condição de instabilidade e fragmentação. Por fim, discutimos o conceito de cenário (GOMES, 2008), compreendido em nossa reflexão enquanto uma possibilidade para problematizarmos e garantirmos exequibilidade a essas duas noções conceituais a partir de nosso referencial, ou seja, das imagens em movimento produzidas pelo cinema.

Se refletirmos acerca das proposições de Harvey (1993), podemos ousar e afirmar que desde a década 1970 vêm ocorrendo mudanças significativas nas práticas culturais, sociais e políticas, as quais não apenas permeiam o ambiente acadêmico, sendo visíveis também nas mais variadas esferas do mundo artístico tal qual a pintura, a música, o teatro, a fotografia e o cinema. É interessante elucidar que existem as mais diversas posicionalidades com relação às "novas" ideias trazidas pela pós-modernidade, sendo uma tarefa complicada encontrar um ponto unificador que seja capaz de conferir-lhe uma coerência interna.

Entretanto, como uma das maiores concordâncias com relação à pósmodernidade é que ela é algum tipo de reação às proposições trazidas pelo Século das Luzes, ou ao menos, como afirma Harvey (1993), enquanto um processo de afastamento de seus ideais é válido optarmos por esse caminho para construirmos nossa reflexão, até mesmo devido ao fato de que os ideais modernos estão presentes na estruturação da noção de espaço público, a qual nos serve como eixo norteador nessa proposta. Como sintetiza Gomes (1996, p. 14),

Para medir a influência do pós-modernismo sobre a geografia, é importante talvez considerar primeiramente a natureza da "geografia moderna", avaliar o progresso, as heranças e, por que não, a legitimidade da manutenção de uma tradição que construiu a identidade da disciplina. Uma geografia pós-moderna é obrigatoriamente tributária de seu passado e, em uma certa medida, reafirma sua tradição, sem a qual as noções de continuidade e de transformação nos escapariam. A tendência pós-modernista, que se insinua na geografia, impõe, assim, um olhar retrospectivo, uma espécie de balanço do que foi a geografia moderna. 
De acordo com o mesmo autor, a modernidade na geografia tem suas raízes nas profundas mudanças ocorridas ao longo do término do século XVII e no decorrer do século XVIII, período correlacionado com o lluminismo na Europa. O autor apresenta sua hipótese na qual a modernidade foi construída a partir de um duplo caráter, ou seja, a partir de dois polos epistemológicos os quais se opunham e, paradoxalmente, se complementavam. Ou seja, a razão, os saberes metódicos e normativos estavam em constante embate com o que o geógrafo chama de "contracorrentes", o domínio que contestava as proposições universalizantes e o poder puro da razão.

De fato, autores como Habermas (1999) e Berman (1982) tendem a qualificar o período moderno a partir de ideais de universalidade, equidade, liberdade, razão e fé na ciência do homem. Entretanto, esse projeto nunca deixou de ter seus críticos. Mudanças trágicas nos contextos sociais, político, cultural e econômico ao longo do começo do século $\mathrm{XX}$, corroboraram para o aparecimento de inúmeros movimentos antimodernistas. Antagônicos as ideias de funcionalidade e racionalidade extrema, esses movimentos contraculturais, exploram uma representação política diferenciada através da incorporação das mais diversas práticas cotidianas.

Surgem então, correntes desconstrucionistas, identificadas com as proposições de autores como Foucault (1976), Derrida (1967), e mesmo proposições filosóficas, como as desenvolvidas por Feyerabend (1989), onde o "tudo é válido" salta aos olhos. É redescoberta a hermenêutica como possibilidade interpretativa para essa nova complexa maneira de experienciar o mundo. A vida cultural passa a ser vista como uma série de textos, em intersecção com outros textos (DUNCAN, 2005), possibilitando as mais diversas interpretações. Em suma, Harvey (1993, p. 49) resume alguns dos principais sentidos da pós - modernidade,

Começo com o que parece ser o fato mais espantoso sobre o pósmodernismo: sua total aceitação do efêmero, do fragmentário, do descontínuo e do caótico que formavam uma metade do conceito baudelairiano de modernidade. Mas o pós-modernismo responde a isso de uma maneira bem particular; ele não tenta transcendê-lo, opor-se a ele e sequer definir seus elementos "eternos e mutáveis" que poderiam estar contido nele. O pós-modernismo nada, e até se espoja, nas fragmentárias e caóticas correntes da mudança, como se isso fosse tudo o que existisse. 
Essa influência é também sentida no mundo das artes, da arquitetura, da comunicação. No cinema, essas tendências são sentidas a partir da criação de uma nova linguagem, preocupada com a alteridade, com o pluralismo de personalidades, por diversas vezes, centradas em um mesmo personagem, o qual tende há vivenciar diversos tempos e espaços de forma simultânea ao longo da narrativa. Uma espécie de misto de eterno déjà vu com imanente sensação de novidade. Como resume Gomes (1996, p. 22),

Estas transformações aparecem também dentro de uma nova linguagem cinematográfica. Dois cineastas são considerados como figuras de proa da pós-modernidade no cinema, David Lynch e Pedro Almodóvar. Eles possuem em comum uma atitude estética bastante característica, representada pela inexplicabilidade de cenas que não acrescentam nenhum sentido à linha narrativa principal; um exagero quase caricatural (personagens e situações inverossímeis); um certo revival dado pelo guarda-roupa, pela música e pelos diálogos; um recurso à ironia como modo de comunicação privilegiado; enfim, como resultado geral, uma estrutura "desorganizada" do cenário.

Essa estética ficcional fragmentada, criada a partir de mosaicos, de colagens, por vezes demasiada "esquizofrênica", para parafrasear Hassan (1988), nos leva a questionar acerca das questões relativas às identidades urbanas e da forma de retratar o mundo de forma coerente. O problema principal se encontra na dificuldade de produzir uma imagem federadora e unitária da cidade, uma vez que essa fragmentação do tecido urbano nos induz a compreensões diversas de cada segmento ou parcela, única e diferenciada, da morfologia das cidades (GOMES e BERDOULAY, 2008).

Esses questionamentos podem ser colocados também as produções ficcionais, uma vez que estas podem ser consideradas enquanto criadoras de realidades. Mudanças vêm ocorrendo, mas afirmar que elas podem ser intituladas sob o nome de "pós-modernidade" é outra coisa. Mesmo sua natureza enquanto reação a modernidade, defendida por alguns, pode ser questionada, pois como discute Gomes (1996, p. 25), sua oposição aos valores estabelecidos pelo culto à razão, "longe de ser o apanágio da pós - modernidade, possui em verdade uma longa lista de antecedentes".

Entretanto, como afirma Harvey (1993), nas últimas décadas, o pós modernismo tornou-se um conceito, com o qual devemos aprender a lidar, não 
podendo mais ser ignorado. Aceitando esse desafio, objetivamos trazer essas concepções para a geografia a partir de um referencial analítico específico, o cinema, problematizando uma questão também específica, as imagens do urbano construídas por Pedro Almodóvar.

Esse cineasta, figura expressiva da Movida espanhola, um movimento de contracultura surgido na Espanha pós - franquista, inicia sua carreira em um contexto de renascimento criativo, no qual jovens artistas buscam maior liberdade, depois de um período de aproximadamente quatro décadas de fechamento e limitação artística (MOSQUERA, 2000). La Movida foi um movimento restritamente urbano, e apesar de ser frequentemente associada à cidade de Madrid, também esteve presente nas esferas artísticas de outras cidades espanholas (HIDALGO, 2009). Em sua estética, explosões de cores berrantes, de figurinos exagerados, com elementos de paródia - esperpéntica, refletindo a linguagem e a forma como esses novos artistas construíam suas vivências espaciais cotidianas.

A cidade deixa de ser uma paisagem harmônica e una, tornando-se uma mistura de colagens, repleta de signos e simbolismos, vivenciada por personagens que, com freqüência, encontram-se confusos acerca do mundo onde estão. Um mosaico onde as diferenças não são apenas aceitas, mas se apresentam como necessárias. Aberta às diferenças, a pluralidade, ao multicultural, onde as disparidades não podem mais ser mascaradas (GASTAL, 2006), a cidade é então vivenciada pelo sujeito cosmopolita, o qual segundo Sennett (1995) é aquele que se movimenta despreocupadamente na diversidade, estando à vontade em situações sem nenhum vínculo com aquilo que the é familiar.

As posicionalidades são as mais diversas e os mais diferenciados adjetivos são utilizados para qualificar, ou ao menos tentar, a cidade na pós-modernidade. As mais comuns são proposições que transitam entre visões economicistas as quais preconizam a influência do capital nos processos de segregação e fragmentação socioespacial do tecido urbano. Autoras como Salgueiro (1998) e Limonad (2000), discutem que essa fragmentação é reflexo do aumento intenso do processo de diferenciação e ruptura de grupos sociais, organizações e territórios que vivemos atualmente. Cidades pós-modernas tendem a privilegiar as singularidades das imagens do urbano construídas principalmente a partir da exaltação de um passado heroico através de formas e monumentos arquitetônicos (SILVA, 2009), onde, não 
raramente, emergem simulacros unidos a transformação do imaginário social e da experiência espacial concreta dos atores sociais.

Zukin (2000) em conformidade com Jameson (1990) afirma ser a exaltação do visual uma das mais importantes características das, utilizando as palavras da autora, paisagens urbanas pós-modernas. Um enigma, um labirinto que é capaz de ludibriar as razões da percepção a partir das novas maneiras dominantes através das quais experienciamos o tempo e o espaço (HARVEY, 1993), criando, da mesma forma, novas imagens do local onde estamos e do que somos nele e a partir dele.

Alguns ousam até mesmo falar em uma suposta perda de autonomia do Estado, o que ocasionaria segundo Habermas (1999), na impossibilidade do Estado em defender seus cidadãos contra efeitos externos causados por decisões de atores que tem origem fora de suas fronteiras. Entretanto, em uma perspectiva antagônica, Gomes (2002, p. 276), esclarece que,

Assim, pós-moderno pode ser, por um lado a reformulação do 'contrato social' que dá origem ao Estado Moderno, no sentido de admitir que esse espaço deve ser a garantia da possibilidade de convivência com o diverso. Em outras palavras, trata-se da flexibilização da norma, no sentido de simultaneamente proteger e limitar a múltipla conformação sociocultural, e nesse ângulo, a sociedade passa a ser vista como um mosaico variado de experiências culturais, unidas por regras que possibilitam compartilhar um espaço comum.

Essa imagem urbana fragmentada imposta pela pós-modernidade, por inúmeras vezes apreendida de maneira extremamente simplista e banal, negligencia o fato de que as cidades são, antes de tudo, compostas por espaços onde exercemos a difícil arte da convivência (GOMES e BEDOULAY, 2008). Composta a partir da reunião de espaços de múltiplas trocas, a cidade é, primeiramente, um tipo de associação política entre as pessoas, ou seja, sua disposição física unida à sua dinâmica sociocomportamental. Nas palavras de Gomes (2002, p. 172)

Dessa maneira, compreendemos que o arranjo físico das coisas é um agente ativo na realização de determinadas ações sociais, e essa ordem espacial é concebida como uma condição para que essas ações se produzam. Isso quer dizer que as práticas sociais, são, em certa medida, dependentes de uma dada distribuição ou arrumação das coisas no espaço. (...) De forma resumida, o espaço geográfico é simultaneamente, o terreno onde as práticas sociais se exercem, a 
condição necessária para que elas existam e o quadro que as delimita e lhes dá sentido.

Nossa reflexão nos remete, assim, a noção de espaço público, concebido em nossa perspectiva enquanto o local, por excelência, onde os sujeitos ganham visibilidade e suas especificidades identitárias são realocadas para um segundo plano, prevalecendo, primeiramente, a condição de cidadãos. Partimos da ideia de que, a partir da vivência dos sujeitos nessas espacialidades públicas, somos capazes de conferir uma unidade a suas experiências, sendo possível, portanto, a criação de uma imagem consolidada e una da cidade.

Não se trata de um espaço utópico ou nostálgico, com referência frequente à ágora grega, mas sim, de um local onde o discurso político é imperante e o princípio da publicidade majoritário a partir de um agir comunicacional. Parece claro que uma análise geográfica da noção de espaço público deve considerar sua materialidade. Entretanto, os espaços públicos, lócus do livre exercício da palavra de acordo com Arendt (1983) e Habermas (1984), são compreendidos aqui também a partir de outras duas dimensões essenciais: as ações e práticas dos sujeitos e as significações que elas implicam.

Um espaço material, preenchido por ações e significados (SANTOS, 2008). Esse espaço é o mise - en - scène da vida pública onde exercitamos a arte da convivência com a pluralidade e a diferença. É o local onde nossos comportamentos são guiados e condicionados pelo lugar físico, reafirmando, na mesma medida, a condição e o estatuto de público desse espaço. Esse lugar, onde os problemas se apresentam e adquirem uma dimensão pública e são resolvidos, tem o seu bom funcionamento condicionado pelo respeito a lei, pela civilidade, criadoras de uma concepção de espacialidade que repousa sobre a democracia e a ordem (GOMES, 2002).

É interessante observar que a presença dos mais diversos grupos sociais nos espaços públicos não é considerada negativa, ou mesmo antagônica, a noção. Desde que essas demandas sociais possam ser transformadas em debates e consequentemente adquiram uma formalização política, essas manifestações são importantes para garantir a renovação do espaço público (VALVERDE, 2007). Em resumo, os mais diferentes grupos socais devem possuir uma representação 
igualitária nos espaços públicos, sem comprometer, dessa forma, seu estatuto de racionalidade e harmonia.

Segundo Gomes (2002), sobre esse espaço observa-se o desenrolar da cena pública, composta por uma gama imensa de manifestações que variam de acordo com a localização espacial e o período temporal onde ocorrem. Essa cena é uma espécie de discurso construído por meio de gestos, atividades, maneiras de se apresentar pelas imagens criadas e lidas a partir de certas especificidades, como a maneira de nos conduzirmos e nos relacionarmos com a diversidade de situações oferecidas e vivenciadas nesse espaço. É valido citarmos Gomes e Berdoulay (2008, p. 12),

A vida pública é cenarização. Isso não quer dizer que haja uma distância entre o real e o imaginário, ao contrário. A cidade sob o ponto de vista defendido aqui é composta por um corpo social, submetido a certas regras de coabitação, estabelecido sobre um espaço que condiciona e qualifica as ações sociais (...) Chamaremos esse conjunto de ações e objetos emanados dessas três esferas política, espacial e da significação - "de cenário". Queremos, a partir dessa denominação, ressaltar o caráter absolutamente interativo dessas três dimensões na construção da vida pública - chamamos de cenário, pois não há independência dessas esferas do sentido que por elas circula. Lugares, sentidos e práticas sociais têm que ser pensados juntos. O espaço da cidade é assim o resultado da articulação dessas três esferas (...)

Nessa perspectiva a cidade aparece como um álbum de imagens que podem ser obtidas a partir de inúmeros pontos de vistas e representações, sendo essa multiplicidade de práticas e atuações a responsável pela geração de uma identidade urbana. Mas como conferir uma unidade a essas representações? Essa parece ser uma das mais relevantes questões, ainda mais quando objetivamos pensar em uma imagem federadora a partir de um contexto pós-moderno, fragmentado e inconstante em sua essência.

Portanto, trazemos a ideia de cenário a qual busca reconectar o conjunto de figurações espacial em sua relação com a estrutura narrativa fílmica. $O$ autor traz esse conceito como uma possível ferramenta para realizarmos uma interconexão entre a geografia e as significações das imagens. Nas palavras do autor, "(...) queremos a partir da palavra cenário reconectar a dimensão física às ações, ou, em 
outras palavras, queremos associar os arranjos espaciais aos comportamentos e, a partir daí, poder reinterpretar suas possíveis significações." (GOMES, 2008, p. 200).

A partir da ideia de cenário podemos observar a cidade em sua mais complexa dinâmica espacial, já que ele implica, simultaneamente, na idéia de ação. O espaço não é um simples palco ou tela onde observamos uma pintura estática, mas sim, um prisma multifacetado, onde imagens se multiplicam e ganham vida a partir da experiência físico-territorial cotidiana dos mais diversos e antagônicos sujeitos.

Nesse artigo, nos interessamos especificamente, pelos cenários que constroem as imagens públicas da cidade de Madrid, ou seja, aquelas que estão intrinsecamente relacionadas com as múltiplas formas de publicidades, como discutem Castro e Teixeira (2008). Essas imagens são provenientes de cenários onde celebramos a vida urbana e onde é possível identificarmos uma linguagem através da qual se identifica um tipo particular de urbanidade (GOMES e BERDOULAY, 2008), a qual caracteriza e diferencia uma espacialidade de outras. Como discute Lynch (1999, p. 53), a imagem de uma cidade é o produto de uma interpretação ou representação coletiva, uma vez que, como ele afirma "parece haver uma imagem pública de qualquer cidade que é a sobreposição de muitas imagens individuais. Ou talvez exista uma série de imagens públicas, cada qual criada por um número significativo de cidadãos.".

Trabalhar com imagens, como as produzidas pelo cinema nos exige a aplicação de certas ferramentas que possam dar conta da noção de sucessão, já que, como aponta Costa (2008), os filmes são produtos de espaços de experiências narrados através do movimento, no qual a análise de significados e sentidos é extremamente densa, e deve obrigatoriamente considerar o movimento de cenas e imagens. Devemos considerar que, quando a composição de uma cena, ou cenário, se altera, a essência mesma dos eventos muda, o que, consequentemente, implica em uma concepção diferenciada de sua geografia.

Toda a ideia desse artigo se pauta sob três noções particulares: a pósmodernidade, sua influência na forma de concebermos e vivenciarmos a cidade e a imagem urbana que podemos construir dela por meio do cinema. Em Almodóvar essas três concepções aparecem de formas específicas, retratadas a partir de um panorama espacial único. 
Passamos agora para a segunda subseção do texto, na qual discutimos as principais abordagens, conceitos e metodologias através das quais a Geografia problematiza as representações das cidades no Cinema. Essa temática vem sendo fortemente discutida por geógrafos que estão voltando sua atenção para às imagens do Cinema e sua potencialidade para análises geográficas.

\section{As Cidades Cinemáticas: abordagens para a Geografia}

Assim como na Geografia, as cidades são um fetiche de longa data na história do Cinema. A grande maioria dos autores que investigam as representações das cidades em sua relação com a linguagem cinematográfica é enfática em apontar que a maneira através da qual elas foram e vêm sendo retradas é diferenciada e fortemente fluida. Essas qualidades não se relacionam unicamente aos gêneros fílmicos, mas também, são concernentes a maior ou menor importância conferida a elas na estrutura narrativa.

Entretanto, para compreender a relação existente entre o Cinema e as cidades é imperante considerarmos o contexto de criação do primeiro nos últimos anos do século XIX. Costa (2008) discute que o cinema surgiu como uma forma de arte urbana. Ele nasceu nas cidades e teve o público urbano como primeiros espectadores. Parece óbvio então que as cidades fossem os cenários privilegiados para serem retrados por cineastas da época. De fato, as cidades modernas compartilham de muitas obsessões do cinema, como a velocidade, as luzes e o movimento (CLAYDON, 2006). Mas, qual a possível explicação do intenso e aparentemente incontornável interesse do Cinema pelas imagens urbanas? E, mais importante, como a Geografia pode contribuir com o debate referente a esse velho conúbio? São essas as perguntas que tentamos responder nessa subseção.

Da simples ideia de planos de fundo para atuação dos personagens presente no cinema mudo americano dos anos 1920, até a exaltação das características de isolamento e solidão propiciadas pela ascensão do Film Noir ${ }^{2}$ na década de 1940, a cidade foi resignificada, repensada e retrabalhada ao longo da tradição

\footnotetext{
${ }^{2}$ O Film Noir é um gênero estético cinematográfico identificado com o final da década de 1940 e 1950. Apresenta características tais quais a exaltação de dramas psicológicos, anomia, solidão, personagens perdendo controle e isolados em pesadelos. Também é relacionada a essa corrente características estéticas tais qual o uso de pouca iluminação, preferência por cenas noturnas onde o contraste entre o preto e o branco é evidente.
} 
cinematográfica. De fato, foi somente com a ascensão do Film Noir que as cidades passam a categoria de elementos integrante da estrutura narrativa, deixando seu papel de palco ou cenário estático para atuação de personagens.

Seria ousado afirmar que nessa corrente estética elas adquiriram centralidade inquestionável, mas acreditamos que a partir das produções Noir cineastas começaram a perceber que as paisagens urbanas poderiam acrescentar significações na trama. As cidades eram utilizadas para intensificar a tensão psicológica dos personagens, da mesma forma, becos e armazéns abandonados pareciam escolhas coerentes para filmar tais narrativas.

É interessante observar, portanto, que gêneros fílmicos particulares exaltam diferentes locações urbanas, ou seja, a escolha espacial deve ser coerente com a estrutura narrativa. No Neorrealismo italiano do final da década de 1950, as abordagens das cidades no cinema mudam drasticamente. Com o crescente interesse pela nova forma de filmar dos documentários, elas passam a representar cenas reais em locações reais, ao contrário do Cinema Noir que utilizava preferencialmente estúdios de gravação. Acreditava-se que com isso um novo apelo poderia ser feito com filmes, a retratação de uma atmosfera com a qual o público apresentasse maior familiaridade. Surgia assim a corrente realista do cinema, ainda inspiração para inúmeras produções e acalorados debates entre pesquisadores que se interessam pelas questões visuais.

Em seu texto sobre a importância da luz nas produções cinematográficas Ford (1994) afirma que com a disseminação do uso de cores no cinema, novas maneiras de representação das cidades foram exploradas por cineastas. $O$ intenso uso de sombras para criação de uma atmosfera desoladora é substituída por imagens quentes e claras que buscam mostrar as cidades como ambientes excitantes e amigáveis. De fato, autores como Kennedy e Lukinbeal (1997) discutem que as cidades tendem a ser representadas no cinema a parir de uma bipolaridade relacionada ou ao sentimento de extremo prazer da vida urbana ou de intensa solidão e frieza das cidades.

Concomitantemente com a ascensão de novas tecnologias, as abordagens acerca das cidades foram alterando-se. Hodiernamente elas são retradas a partir de uma imensa variedade de formas e essas representações estão desafiando pesquisadores de inúmeras áreas do conhecimento, os quais buscam, a partir de 
conceitos, metodologias e abordagens interpretar suas possíveis significações e simbolismos. Na Geografia, o interesse pelas imagens em movimento é antigo.

Azevedo (2009) nos recorda que a aproximação entre os geógrafos e os materiais fílmicos deu-se desde a criação do último no final do século XIX. $O$ chamado "Primeiro Cinema" foi rapidamente abraçado pelos geógrafos, pois devido à falta de estrutura narrativa e da inexistência ficcional, características que foram atribuídos aos filmes posteriormente, ele era um excelente meio para mostrar a realidade. Isso se deve, possivelmente, ao fato de que os primeiros filmes exibidos mostravam cenas do cotidiano. As imagens de operários saindo de fábricas, de pessoas fazendo compras e de bebês se alimentando eram comuns nos primórdios da exibição cinematográfica.

Por conseguinte, as primeiras aproximações entre a geografia e o cinema se deram a partir de interesses educacionais, ou seja, os filmes - e sua até então inquestionável verossimilhança com a realidade - eram utilizados como suporte pedagógico para o ensino em geografia, visto que possibilitavam uma "viagem" ao campo de interesse. Segundo essa perspectiva, eles demonstravam com maior precisão as dinâmicas sociais e naturais, pois se constroem a partir da ideia de movimento e forma. Isso os tornava, pois, mais aptos do que outras formas imagéticas, como a fotografia e a pintura (AITKEN e DIXON, 2006).

Entretanto, é somente a partir do final da década de 1970 que se observa um interesse mais denso dos geógrafos pelas imagens em movimento. Apoiados nas proposições trazidas pela Nova Geografia Cultural, pesquisadores começam a problematizar filmes buscando, assim, uma nova fonte de pesquisa para análises geográficas. Os conceitos e metodologias utilizados são múltiplos e os posicionamentos costumam variar entre abordagens cognitivas e humanistas (KENNEDY e LUKINBEAL, 1997) e estudos socioculturais (AITKEN e ZONN, 1994).

As pesquisas mais comuns buscam interpretar as paisagens urbanas em filmes, como visto em Costa, 2005a e 2005b; Harper, 2010; D’Lugo, 2010 e Clarke, 1997, entre outros. A paisagem cinemática ajuda a compreender a construção da materialidade e também da subjetividade nos filmes, pois como lembra Escher (2006), a paisagem é vista nas abordagens como parte da psique dos personagens. Outros optam por discutir a noção de paisagem como construída e construtora a partir de um viés do realismo cinematográfico. Existem ainda as paisagens 
imaginárias ou futuristas dos filmes de ficção científica, as paisagens textuais, etc.. Resumindo, os posicionamentos são múltiplos e, dependendo do foco de interesse ou pergunta de partida do pesquisador, as abordagens são infinitas.

Nesse artigo também voltamos nossa atenção para a temática das cidades, problematizadas a partir da noção de espaços públicos. É imprescindível apontar que essa é uma escolha conceitual relacionada a uma pergunta particular, ou seja, inúmeras outras possibilidades podem ser exploradas tendo como base os filmes de Almodóvar.

\section{Os espaços públicos da Madrid de Pedro Almodóvar e suas} significações: normatividades, transgressões e visualidades

A filmografia de Pedro Almodóvar é composta por dezoito filmes, os quais apresentam inúmeras similaridades entre si. Nesse artigo, vamos abordar uma delas: a ênfase no espaço urbano da cidade de Madrid, cenário utilizado pelo cineasta na composição de suas narrativas. A aproximação do cineasta com a cidade perpassa seus filmes. Madrid foi palco para o desenvolvimento de um dos movimentos culturais mais importantes da cena artística espanhola, a Movida, a qual influenciou fortemente a estética de Almodóvar, especialmente em seus primeiros oito filmes.

A grande maioria dos autores que voltaram seu olhar para os filmes do cineasta insistem em enfatizar a dificuldade de caracterizar as produções de Almodóvar dentro de um gênero ou corrente estética particular. Em sua filmografia observamos uma mixité de elementos que nos leva a considerar a intensa complexidade que abraçamos quando objetivamos problematizar seus filmes. Entretanto, existem alguns elementos que auxiliam na produção de uma ideia federadora da representação da cidade e seus espaços públicos na filmografia de Almodóvar. Esses elementos estão relacionados principalmente com a ideia de visualidade, ou seja, com a nova imagem que Pedro Almodóvar cria da cidade de Madrid.

Santana (2009) reflete acerca da importância da influência da Movida Madrileña nas produções do cineasta. $O$ autor discute que a mudança do contexto cultural e político da Espanha no início dos anos 1980 devido a queda da ditadura 
franquista propiciou a artistas um novo fôlego para produções diferenciadas e irreverentes, até então inéditas na cena cultural espanhola. Pedro Almodóvar estava incluído nesse turbilhão de mudanças e seus filmes são um interessante referencial demonstrativo dessa nova fase.

De fato, a Madrid que o cineasta constrói em seus filmes, cenário e personagem, é diferenciada e representa um novo universo, onde questões de transgressão, normatividade, visualidade são exaltadas aos olhos. Esse mise-enscène é carregado de significações e simbolismos que remetem a vontade do cineasta de apresentar, explorar e valorizar múltiplas facetas da sociedade espanhola a partir de suas narrativas.

Nesse artigo, nos focamos particularmente na forma como Almodóvar constrói os espaços públicos de Madrid, bem como as práticas que são conteúdos desses espaços. A partir da perspectiva discutida anteriormente, acreditamos que a partir da análise dos espaços públicos, bem como, das performances dos personagens nesses espaços, somos capazes de obter uma abordagem federadora, capaz de produzir uma imagem da cidade de Madrid nas produções do cineasta.

D'Lugo (2011) discute que as representações da paisagem espanhola no cinema sempre esteve carregada de elementos simbólicos e valores ideológicos. Tradições folclóricas são frequentemente evocadas para conferir aos filmes uma abordagem nacionalista, ou seja, capaz de identificar a paisagem com sua estrutura cultural. $O$ autor recorda o quanto a ditadura de Franco marcou a produção cinematográfica espanhola, época em que a paisagem rural e os benefícios da modernização social e cultural foram enfatizadas por cineastas.

Almodóvar participou do turbilhão de mudanças proporcionado pela queda de Franco. O cineasta apresenta, então, acontecimentos, personalidades de caráter excepcionais, bem como uma cidade dinâmica, cenários de múltiplas trajetórias. Em suas primeiras produções, Almodóvar constrói uma Madrid que ri, com caricaturas divertidas que representam o período de liberdade, de vida democrática e o fim da censura franquista. Hábitos sociais peculiares entrelaçados com comportamentos que recordam o tradicionalismo são pontos chaves de seus primeiros filmes.

Madrid representa a possibilidade de tornar todo esse processo visual, ou seja, o cineasta cria uma cidade na qual a visualidade é imperante. Sua estética, fortemente identificada com o pós-modernidade, influenciou inúmeros outros 
cineastas da cena espanhola. A destruição, ironia e caricaturização de alguns valores proporcionou a coexistência de dois estilos de vida, de cultura, de práticas, que estavam despontando na Espanha na década de 1980. E Madrid é o cenário que proporciona essa nova leitura.

Ela é fragmentada, dividida, cenário onde os mais diferentes sujeitos coexistem, em harmonia ou não. É enfatizada a performance desviante e transgressiva de inúmeros personagens, bem como, práticas normativas que demonstrar o desejo da sociedade espanhola de mudança sem perda de suas raízes culturais. De fato, esse movimento dialético, de modernização cultural em contraponto ao fortalecimento de elementos tradicionais é muito bem explorado pelo cineasta em inúmeros filmes. Seus personagens, geralmente ludibriados por dramas pessoas, buscam estabilidade em um ambiente que é fluido, dinâmico e em contaste mudança.

Filmes como "O que eu fiz para merecer isto?" e "Mulheres a beira de um ataque de nervos" trazem essa dinâmica de forma evidente. A Madrid dos filmes representa um cenário de possibilidades para as personagens, as quais, geralmente, optam por caminhos desviantes. A representação dos espaços públicos é condizente, permeando ora entre espaço normativo e ora caracterizado por elementos de transgressão. Esse fato é interessante quando recordamos que os espaços públicos tendem a ser caracterizado pelo respeito às normas, condição primordial para sua existência. Na filmografia do cineasta, eles têm um caráter duplo, normativo e possibilidade para transgressões.

Em suas produções posteriores, como "Ata-me", "De Saltos Altos", "Kika" e "A Flor do meu Segredo", Almodóvar mantém sua originalidade característica, bem como, a importância de Madrid para suas tramas. "Ata-me" traz uma história que mistura a transgressão e a normatividade, cada qual alinhada a um cenário específico. Novamente, os espaços públicos de Madrid são cenários para práticas desviantes e ao longo do filme podemos observar algumas características muito interessantes e que, com maior ou menor intensidade, caracterizam de forma geral a filmografia do cineasta. Se levarmos em consideração elementos formais da linguagem cinematográfica, podemos apontar que decisões relacionadas à iluminação, às cores, bem como a posicionamento de câmera no momento de filmagem são fatores de extrema importância na estrutura narrativa de filmes, pois 
aderem significados ao filme. Gêneros fílmicos tendem a ser, geralmente, caracterizados a partir desses elementos.

Na filmografia de Pedro Almodóvar é difícil, se não impossível, observar um padrão que confira uma identidade fechada a sua produção. Entretanto, em "Átame”, o cineasta faz uso de muitos elementos que podem ser encontrados na grande maioria de seus filmes se observamos com um olhar cuidadoso. O primeiro deles é o uso panoramas como plano para retratar cenas em espaços urbanos, ou como estamos sugerindo nesse artigo, espaços públicos. Esse tipo de escolha garante ao cineasta uma grande profundidade de campo e implica em um enquadramento que não se restringe fortemente em nenhum personagem único, gerando assim, uma visão geral do cenário e da interação entre os sujeitos.

A grande maioria das cenas nos espaços públicas na filmografia de Almodóvar é noturna, como observamos em "A lei do Desejo", "A Flor do meu Segredo", "De Saltos Altos". Ou seja, com iluminação reduzida, Almodóvar joga, brinca com uma imensa mixité de elementos, bem como, de gêneros. $O$ cineasta comumente utiliza de características do Cinema Noir em conjunção com elementos de Cinema de Paródia e Mudo. Ou seja, a Madrid que ele apresenta é subversiva, é noturna, fragmentada por dois modos de vida e de práticas que são opostos e de certa forma, complementares.

"Tudo sobre minha mãe" é uma das mais conhecidas tramas de Almodóvar e possivelmente seu filme mais geográfico, se assim podemos colocar. A personagem central transita entre duas espacialidades urbanas distintas, Madrid e Barcelona e ambas são qualificadas e simbolizadas por Almodóvar de forma diferenciada. Esse filme é particularmente interessante devido à ênfase que o cineasta confere aos espaços públicos de ambas as localidades.

Barcelona representa a transgressão, e os espaços públicos do filme foram coerentemente construídos para interagir com questões como prostituição e marginalidade, enquanto Madrid representa o apego às tradições e uma forma pacata de vivência cotidiana para os personagens. Almodóvar também valoriza alguns pontos turísticos de ambas as cidades, evocando novamente o quanto a visualidade é forte em suas produções. Por visualidade compreendemos o ato de enfatizar determinado aspecto claramente, sem uso de metáforas e outros elementos correntes na linguagem cinematográfica. 
Os filmes posteriores demonstram maior maturidade do cineasta, representada tanto a partir de uma construção mais complexa e abstrata de estruturas narrativas quanto nos cenários. "Fale com ela", "Má Educação" e "Volver", os filmes posteriores, entrelaçam elementos de caráter mais abstrato para criar uma atmosfera mais introspectiva e íntima entre os personagens. É interessante observar que nestes três filmes Almodóvar faz pouco uso de cenas em espaços públicos, sendo a representação da cidade praticamente ínfima nas tramas. Os personagens e suas dinâmicas estão restritos a espaços privados, ou seja, a cenários íntimos e reclusos.

Não é objetivo no texto tentar decifrar de alguma forma o que o cineasta tinha em mente quando criou seus filmes. Isso seria um trabalho com caráter epistemológico completamente diferenciado do que pretendemos. Nosso objetivo é compreender a construção dos cenários, dos espaços públicos a partir de uma coerência própria e interna na estrutura narrativa, ou seja, pouco nos interesse a intenção do cineasta. Não estamos afirmando de forma alguma que eles não representam as ideologias e que não trazem elementos simbólicos que foram impostos por Almodóvar. Isso é claro, visto que toda e qualquer produção, principalmente artística, é fruto de decisões que acabam por demonstrar a intencionalidade de seu criador. Entretanto, nesse artigo, interessa-nos sim, o universo criado pelos filmes a partir da própria coerência interna das tramas.

A produção do cineasta é plural e o contínuo desrespeito por formalismos, que costuma ser observado no cinema, seja mesmo o motivo da riqueza de Almodóvar. E, certamente, é o motivo do alto nível de complexidade que abraçamos quando depositamos nosso olhar sobre sua filmografia. Ele possui uma forma diferenciada de criar, de filma e de montar, e sua estética, fortemente identificada com a pós-modernidade, nos confere uma imagem de Madrid que é pouco usual no cinema.

Nesse artigo exploramos a questão da transgressão, da normatividade e da visualidade. Entretanto, o campo permanece aberto e com inúmeros questionamentos que podem ser problematizados a partir dos filmes do cineasta. $\mathrm{Da}$ mesma forma, é imperante que nós geógrafos, adotemos uma postura crítica e inovadora que seja capaz de produzir abordagens densas e criativas. Nesse momento, o cinema nos parece um interessante estímulo para tal. 


\section{Palavras Finais}

Depois de mais de cem anos desde a primeira exibição cinematográfica realizada pelos irmãos Lumière no Grand Café em Paris no ano de 1896, poucos ousam afirmar que o cinema não está entre as principais expressões culturais da sociedade contemporânea. De fato, sua importância, e consequente influência, é tamanha que o Cinema conseguiu perpassar a esfera artística e se tornar campo de estudos para inúmeras áreas do conhecimento acadêmico. Disciplinas como a Sociologia, Antropologia, Psicologia entre outras, vêm voltando seu olhar para as imagens em movimento, problematizando a partir delas um grande número de temáticas, desenvolvimento inúmeras metodologias e posicionamentos conceituais, muitos dos quais, inéditos e inovadores.

Entretanto, na Geografia a produção ainda é tímida e os poucos trabalhos demonstram o esforço de pesquisadores para fortalecer a abordagem consolidando, assim, um novo subcampo investigativo. Esse artigo representa um genuíno esforço nesse sentido, utilizando a filmografia de um cineasta particular para evidenciar a multiplicidade de possibilidades que podem ser tecidas entre a Geografia e o Cinema.

Não podemos deixar de apontar que pesquisas de grande relevância já foram realizadas com base nos filmes de Almodóvar, entretanto, para a geografia esse campo ainda permanece aberto, ou seja, nos garante a possibilidade de realizar uma abordagem autêntica e inédita, utilizando diferentes ferramentas, metodologias, conceitualizações e noções. Essa é uma das maiores provas de que a geografia é uma ciência viva, dinâmica, aberta e plural (GOMES, 2010), capaz de brindar seus "filhos" com o mais rico e diverso campo investigativo.

Não são raras as associações entre a produção do cineasta com a questão da marginalidade ou mesmo com discussões envolvendo noções de psicologia e educação entre outras. Entretanto, é possível afirmar, também como espectadora e fã de seus longas, que Almodóvar é mais que isso e nos dá condição para pensar o diferente, o novo, o polêmico e o imprevisível.

Gostaríamos de terminar esse artigo citando um trecho de uma entrevista concedida por Pedro Almodóvar, no qual o cineasta respondia perguntas sobre os filmes "Fale com ela" e "Má Educação", 
Quando se faz um filme, não se pára de desvendar mistérios, de fazer descobertas. Quando se escreve, quando se filma, quando se faz a montagem e mesmo quando se faz a promoção, descobrem-se coisas sobre a história que o filme conta, sobre si mesmo e sobre os outros. É certamente o que se procura de forma inconsciente quando se faz cinema: entrever os enigmas da vida, resolvê-los ou não, mas, em todo caso, revelá-los. O cinema é a curiosidade, no verdadeiro sentido da palavra. A curiosidade que pode ser o motor de uma grande história de amor, de um grande filme, como as decisões importantes na vida. (ALMODÓVAR, 2008, p. 259).

Essa citação de Almodóvar representa de forma singular a motivação de muitos pesquisadores que vêm voltando seu olhar e interesse para o cinema. Como afirmam Castro, Gomes e Corrêa (1996), a geografia é a ciência das explorações. Explorações de novos temas, de novas possibilidades e ferramentas explicativas. Nesse sentido, o cinema, e suas descobertas, é uma temática verdadeiramente apaixonante. Esse artigo representa um esforço no sentido de demonstrar isso.

\section{Referências}

AITKEN, Stuart C.; ZONN, Leo E. Re-presenting the place pastiche. In: AITKEN, Stuart C.; ZONN, Leo E (Orgs). Place, Power, Situation, and Spectacle: a Geography of Film. Maryland: Rowman \& Littlefield Publishers, 1994, pp. 3 - 25.

AITKEN, Stuart C.; DIXON, Deborah P. Imagining geographies of film. In: Erdkunde, Dezember 2006, pp. 326 - 336.

ARENDT, Hannah. A condição humana. Rio de Janeiro: Forense-Universitária, 1983.

AZEVEDO, Ana Francisca de. Geografia e Cinema. In: CORRÊA, Roberto Lobato; ROSENDAHL, Zeny. Cinema, Música e Espaço. Rio de Janeiro: EdUERJ, 2009. pp. $95-127$.

BERMAN, Marshall. All that is Solid Melts into Air. New York: Simon and Shuster, 1982.

CASTRO, Iná Elias de; GOMES, Paulo Cesar da Costa; CORRÊA, Roberto Lobato.

Explorações Geográficas. Rio de Janeiro: Bertrand Brasil, 1996. 
CASTRO, Iná Elias de; TEIXEIRA, Ataíde. Imagens Públicas da desordem no Rio de Janeiro: uma nova ordem ou o "ridículo de Pascal?". In: Revista Cidades, v. 5. N. 7, pp. 93 - 108, 2008.

CLARKE, David B. Introduction: previewing the cinematic city. In: CLARKE, David B. (Org). The cinematic city. London: Routledge, 1997.

CLAYDON, Anna. CityScope: The cinema and the city. In: GBER, n. 5, v. 1, 2006, pp. $57-68$.

COSGROVE, Denis. Geography is everywhere: culture and symbolism in human geography. In: GREGORY, David; WALDORF, R. (Orgs). Horizons in Human Geography. Londres: MacMilan, 1989.

COSTA, Maria Helena Braga e Vaz da. Geografia Cultural e cinema: práticas, teorias e métodos. In: ROSENDAHL, Zeny; CORRÊA, Roberto Lobato (Orgs). Geografia: temas sobre espaço e cultura. Rio de Janeiro: EdUERJ, 2005a, pp. 43 - 78.

As paisagens urbanas e o imaginário fílmico. In: VALENÇA, Márcio Moraes; COSTA, Maria Helena Braga e Vaz da (Orgs). Espaço, cultura e representação. Natal: EdUFRN, 2005b, pp. 81 - 96.

. Cinema e arquitetura: percepção e experiência do espaço. In: Revista Cidades, v. 5. N. 7, pp. 63 - 78, 2008.

D'LUGO, Marvin. Landscape in Spanish Cinema. In: HARPER, Grame; RAYNER, Jonathan (Orgs). Cinema and Landscape. Chicago: The University of Chicago Press, 2010, pp. $117-130$.

DERRIDA, Jacques. De La Grammatologie. Paris: Les Éditions Minuit, 1967.

DUNCAN, James. The city as text. The politics of landscape interpretation in Kandyan Kingdom. New York: Syracuse University, 2005.

ESCHER, Anton. The geography of cinema. A cinematic world. In: Erdkunde, Dezember, 2006, pp. $307-314$.

FEYERABEND, Paul. Contra o método. Rio de Janeiro: Francisco Alves, 1989.

FORD, Larry. Sunshine and shadow: lighting and color in the depiction of cities on film: IN: AITKEN, Stuart C.; ZONN, Leo E. Place, Power, Situation and Spectacle: A Geography of Film. Maryland: Rowman \& Littlefield Publishers, 1994, pp. 119 136.

FOUCAULT, Michel. Histoire de la Sexualite I. La volonté de savoir. Paris: Gallimard, 1976. 
GASTAL, Susana. Cidade na pós-modernidade: repensando a esfera pública. In: UNIrevista, vol. 1, n. 3, 2006.

GOMES, Paulo Cesar da Costa. Geografia e Modernidade. Rio de Janeiro: Bertrand Brasil, 1996.

A condição urbana. Ensaios de geopolítica da cidade. Rio de Janeiro: Bertrand Brasil, 2002.

Cenários para a geografia: sobre a espacialidade das imagens e suas significações. In: ROSENDAHL, Zeny; CORRÊA, Roberto Lobato. (Orgs) Espaço e Cultura: Pluralidade Temática. Rio de Janeiro: EdUERJ, 2008.

GOMES, Paulo Cesar da Costa; BERDOULAY, Vincent. Apresentação - Cenários da Vida Urbana: Imagens, Espaços e Representações. In: Revista Cidades, v. 5. N. 7, pp. 9 - 14, 2008.

HABERMAS, Jürgen. Mudança estrutural da esfera pública. Rio de Janeiro: Editora Tempo Brasileiro, 1984.

HABERMAS, Jürgen. O Discurso Filosófico da Modernidade. Lisboa: Publicações Dom Quixote, 1999.

HARPER, Graeme. Introduction - Cinema and Landscape. In: HARPER, Grame; RAYNER, Jonathan (Orgs). Cinema and Landscape. Chicago: The University of Chicago Press, 2010, pp. $13-28$.

HARVEY, David. Condição pós-moderna: uma pesquisa sobre as origens da mudança cultural. São Paulo: Edições Loyola, 1993.

HASSAN, Ihab. Fazer Sentido: As Atribulações Do Discurso Pós-Moderno. In: Revista de Ciências Sociais, pp. 47 - 76, 1988.

HIDALGO, João Eduardo. O movimento de contracultura La Movida madrilena e o aparecimento de Pedro Almodóvar. In: Anais do Intercom - Sociedade Brasileira de Estudos Interdisciplinares da Comunicação XIV Congresso de Ciências da Comunicação na Região Sudeste - Rio de Janeiro - 7 a 9 de maio de 2009, pp. 1 -15 .

JAMESON, Fredric. Espaço e Imagem. Teorias do pós - moderno e outros ensaios. Rio de Janeiro: Editora da UFRJ, 2004.

KENNEDY, Christina; LUKINBEAL, Chris. Towards a holistic approach to geographic research on film. In: Progress in Human Geography, n.21, v. 1, 1997, pp. $33-50$. 
LIMONAD, Ester. A cidade na pós-modernidade: entre a ficção e a realidade. In: GEOgraphia, ano II, n. 3, 2000.

LYNCH, Kevin. A imagem da cidade. São Paulo: Martins Fontes, 1999.

MOSQUERA, José Sánchez. Democratic Gays, Modern Gays. The Construction of Homosexual Characters in Spanish Films During the Transition (1975-1978). 2000. Tese. Faculty of Graduate Studies and Research, Carleton University. Ottawa, Ontario.

ROSE, Gillian. Visual Methodologies. An introduction to the interpretation of visual materials. Trowbridge: Cromwell Press, 2001.

SALGUEIRO, Teresa Barata. Cidade pós-moderna: espaço fragmentado. In: Revista Território, ano III, n. 4, 1998.

SANTANA, Gilmar. Riso, Lágrima, Irônia, Tratados: Pedro Almodóvar genialidade e paradoxo em construção permanente. 2007. 365 f. Tese. Programa de Pós - Graduação em Sociologia, Universidade de São Paulo.

SANTANA, Gilmar. A cidade no cinema - Pedro Almodóvar: uma experiência de afetos - da Movida à maturidade, a Madrid de um cineasta. In: Cadernos Ceru, série 2, vol. 20, n.1, 2009, pp. $33-60$.

SANTOS, Alice Nataraja Garcia. Espaço Público como imagem da cidade: interpretações de um geógrafo no cinema. In: Revista Cidades, v. 5. N. 7, pp. 79 92, 2008.

SENNETT, Richard. O declínio do homem público. São Paulo: Companhia das Letras, 1995.

SILVA, Valéria Cristina Pereira. A cidade no labirinto: descortinando metáforas da pós-modernidade. In: Sociedade \& Natureza, Uberlândia, v. 21, n. 1, pp. 147-158,. 2009.

VALVERDE, Rodrigo Ramos Hospodar Felippe. A transformação da noção de espaço público. A tendência a heterotopia do Largo da Carioca. 2007. 255 f. Tese. Doutorado em Geografia. Universidade Federal do Rio de Janeiro.

ZUKIN, Sharon. Paisagens urbanas pós-modernas: mapeando cultura e poder. In: ARANTES, Antônio A (Org). O espaço da diferença. Campinas: EdCampinas, pp. $80-103,2000$.

(Recebido em 07.11.2012. Aceito em 18.04.2013) 